\title{
The Associations between Substance Use, Sexual Behavior, Deviant Behaviors and Adolescents' Engagement in Sexting: Does Relationship Context Matter?
}

\author{
Joris Van Ouytsel ${ }^{1} \cdot$ Michel Walrave $^{1} \cdot \mathrm{Yu} \mathrm{Lu}^{2} \cdot$ Jeff R. Temple $^{2} \cdot$ Koen Ponnet $^{3}$
}

Received: 4 June 2018 / Accepted: 13 July 2018

(c) Springer Science+Business Media, LLC, part of Springer Nature 2018

\begin{abstract}
While prior research has identified multiple associations between engagement in sexting and risky behaviors, most existing studies do not take into account the contexts in which sexting occurs. The present study extends prior research by examining whether the associations between adolescents' sexting behavior and engagement in substance use, sexual behaviors, and deviant behaviors differ depending on the relational context (within or outside of a romantic relationship) in which young people engage in sexting. Results from a survey of 1187 secondary school students $(61.3 \%$ girls, $n=728)$ between 16 and 22 years old $(M=17.82$ years; $S D=0.88)$ revealed that sexting with a romantic partner is not a significant marker of engagement in risk behaviors. However, single youth who engage in sexting outside of a romantic relationship are more likely to report substance use, relative to their non-sexting counterparts. These findings underscore the need to use more nuanced measures to investigate sexting and for sexual education initiatives to integrate messages about substance use.
\end{abstract}

Keywords Sexting $\cdot$ Risk behaviors $\cdot$ Adolescents $\cdot$ Internet and abuse

\section{Introduction}

Adolescence is a period of identity development and sexual exploration, and generally involves the initial development of romantic relationships (Collins et al. 2009). Digital media offers adolescents with additional venues through which they can explore, develop, sustain, and experiment with their romantic and sexual relationships. Through sexting, the sending of self-made sexually explicit photographs, adolescents can "construct and present their sexual selves" (Šmahel and Subrahmanyam 2014; p. 71). A recent metaanalysis found that $14.8 \%$ of youth have sent a sexting image, with a $95 \%$ confidence interval between 12.8 and

Joris Van Ouytsel

joris.vanouytsel@uantwerp.be

1 Department of Communication Studies, University of Antwerp, Sint-Jacobsstraat 2, Antwerp 2000, Belgium

2 Department of Ob/Gyn, UTMB Health, 301 University Blvd, Galveston, TX 77555-0587, USA

3 Department of Communication Studies, IMEC-MICT-Ghent University, Korte Meer 11, Ghent 9000, Belgium
16.8\%. The mean worldwide prevalence for receiving sexting images was around $27.4 \%$, with a $95 \%$ confidence interval between 23.1 and $31.7 \%$ (Madigan et al. 2018).

Sexting has been conceptualized differently across studies, which makes it difficult to compare findings (Van Ouytsel et al. 2018a). Some studies have defined sexting as the sending of sexually explicit text messages and self-made sexually explicit pictures (e.g., Dake et al. 2012; Houck et al. 2014; Rice et al. 2012). Combining two distinct behaviors (e.g., writing a sexually explicit text versus taking a photograph) with arguably different degrees of risk within one item could muddle the accuracy of the found associations. Other researchers, therefore, define sexting exclusively as the sending of self-made sexually explicit pictures (e.g., Temple and Choi 2014; Mitchell et al. 2012). In this study, we adopt a narrow definition which is limited to the sending of images, as the risks of reputational damage after the unauthorized distribution of self-made sexually explicit pictures are arguably higher than with the sending of textonly messages (Van Ouytsel et al. 2015).

Sexting may be considered a risky behavior, as the images can be forwarded to others who were not intended as the receivers. This can lead to reputational damage or bullying (Van Ouytsel et al. 2014). Given these potential risks, 
several studies have focused on the associations between adolescents' sexting and known risk behaviors. This line of research has found that sexting is associated with engagement in a variety of risky behaviors, such as substance use, sexual (risk) behaviors, and deviant behaviors (Temple and Lu 2018).

The research into the (health) risk behaviors associated with sexting is important for practice, as inquiring about adolescents' engagement in sexting could be used to assess whether they are also more prone to be involved in risk behaviors more generally (Ybarra and Mitchell 2015). This area of research can also contribute to our theoretical understanding of the phenomenon. The associations between sexting and risk behaviors can be expected from the theoretical lens of problem behavior theory (Jessor 2014), which hypothesizes that problem and risk behaviors share similar underlying individual and ecological risk factors. Furthermore, the associations between sexting and risk behaviors by adolescents can be further explained from a lifestyle-routine activities theory perspective, as engaging in a deviant or risky lifestyle could increase the risk of becoming a victim of online types of violence (i.e., sexting under pressure or other sexting incidents) (Wolfe et al. 2016)

\section{Associations between Adolescent Sexting and Risk Behaviors}

A first area of research on the associations between adolescents' sexting and risk behaviors investigates how adolescents' engagement in sexting is associated with sexual behaviors, and sexual risk behaviors. Longitudinal research established a relationship between asking for a sexting message, sending a sexting message, and sexual behavior over time (Temple and Choi 2014). Sending sexually explicit text messages has also been associated with subsequent sexual behaviors (Brinkley et al. 2017). Crosssectional studies found that adolescents' engagement in sexting is linked with involvement in different types of sexual behavior (ranging from oral sex to vaginal or anal sex) (Houck et al. 2014; Ybarra and Mitchell 2014; Rice et al. 2018). Furthermore, the sending of self-made sexually explicit pictures among adolescents has been crosssectionally associated with sexual risk behaviors, including having a higher average number of sexual partners in the year prior to the study (Ybarra and Mitchell 2014; Temple et al. 2012), using alcohol or drugs before sex (Temple et al. 2012), and failure to use a condom during the last sexual intercourse (Rice et al. 2018; Rice et al. 2012). Longitudinal studies produced mixed results with one study not finding any associations between sending self-made sexually explicit photographs and sexual risk behaviors (Temple and Choi 2014) and another finding an association between sending sexually explicit text messages and early sexual debut, having had multiple sexual partners, and substance use prior to sexual intercourse (Brinkley et al. 2017).

Using a broad definition of sexting that encompassed the sending of sexually explicit text messages and self-made images, Dake et al. (2012) found that sexting was associated with being a victim of bullying and cyberbullying. West et al. (2014) found an association between sending and receiving sexually explicit text messages and cyberbullying victimization among adolescent girls (West et al. 2014). By applying a deviance framework to investigate sexting, other studies have focused on the links between adolescents' sexting and deviant behavior such as delinquency (Dake et al. 2012; Lee et al. 2016). Lee et al. (2016) found a link between sexting and deviant behavior (a sum score of different delinquent behaviors). However, the behaviors that were assessed to measure deviant behavior ranged from health risk behaviors such as "drinking" or "smoking" to more severe deviant behaviors such as "stealing money" or "having sex for money". As such, the severity of these items varied and could have skewed the results.

Engagement in sexting has also been linked to adolescents' substance use. Dake et al. (2012) found that broadly defined sexting behavior was associated with cigarette smoking, marijuana use, and alcohol use (i.e., alcohol use in the 30 days prior to the study, and heavy episodic drinking). Temple et al. (2014) found an association between the sending of self-made sexually explicit pictures and a composite question measuring whether the respondent had ever used "alcohol, marijuana, or other illicit substances" (Temple et al. 2014). In a European study, Ševčíková (2016) found an association between alcohol use and a broad measure of sexting, defined as "sending or posting a sexual message" (Ševčíková 2016, p. 158).

Studies vary in how risk behaviors like substance use and delinquency are measured. Some studies investigate the associations between sexting and individual risk behaviors (e.g., Dake et al. 2012), while others use composite scores to assess different risk behaviors (e.g., combining several substance use items, such as alcohol, marijuana, and other drugs into one measure; Temple et al. 2014). These differences in measurement cloud our understanding of the specific risk behaviors that sexting may be associated with.

\section{The Importance of Sexting Context}

Previous studies investigating the associations between sexting and risk behavior do not consider contextual factors for engagement in sexting, such as differences in sexting partner types (Barrense-Dias et al. 2017). From a theoretical perspective, the Differential Susceptibility to Media Effects Model (Valkenburg and Peter 2013) underscores the 
importance of social contexts in reinforcing or overriding "dispositionally and developmentally induced media preferences and effects" (Valkenburg and Peter 2013, p. 234). Several scholars have argued that the link between sexting and risk behavior might differ when taking into account the relationship context in which the messages were sent (Barrense-Dias et al. 2017; Van Ouytsel et al. 2018a), e.g., whether sexting occurred within or outside of a romantic relationship. This study will account for the relationship context in which sexting takes place.

A potential risk associated with sexting is that the picture might be forwarded or shown to others without consent (Lippman and Campbell 2014). The perceived likelihood of this happening could depend on the context in which the sexting behavior takes place. It could be argued, for instance, that sexting might constitute less of a risk when the picture is sent within a romantic relationship, in which more trust is established as opposed to sexting outside of a romantic relationship, where the risk of unauthorized distribution of the sexting pictures might be relatively higher (Van Ouytsel et al. 2017). Engagement in sexting has been associated with sensation seeking (Van Ouytsel et al. 2014) and impulsivity (Temple et al. 2014). More specifically, Van Ouytsel et al. (2017) found that engagement in sexting outside of a romantic relationship was uniquely influenced by the perceptions of thrill and excitement that were associated with the behavior, whereas such a relationship was absent for sexting within the context of a romantic relationship. Youth who engage in sexting outside of a romantic relationship might therefore be more risk seeking than those who send self-made sexually explicit photographs within a romantic relationship. Consequently, it can be hypothesized that the associations between sexting and known risk behaviors might differ when taking into account the intended recipient.

In our analyses, we will control for gender, age, sexual orientation, living arrangement, smartphone ownership, amount of social networking site use, and subscription to a mobile data plan, as these control variables might be associated with sexting. For instance, a review of the literature by Klettke et al. (2014) found that the results of previous studies with regard to the relationship between gender and the sending of sexually explicit images among adolescents are mixed. Some studies found no gender differences and others found that female adolescents were more likely to send sexting messages than their male counterparts. Several previous studies found a significant relationship between age and sending sexting images, with older adolescents being more likely to send sexting images than younger adolescents (Houck et al. 2014; Rice et al. 2012; Wood et al. 2015; Ybarra and Mitchell 2014). Previous studies also found that young people who identified as nonheterosexual were more likely to have engaged in sexting than those who did not identify as such (Rice et al. 2014; Rice et al. 2012; Ybarra and Mitchell 2014). Results on the relationship between family situation and adolescents' engagement in sexting are equivocal, with one study finding no significant relationship (Van Ouytsel et al. 2014) and another finding a significant association between engagement in sexting and parental marital status (Vanden Abeele et al. 2014). Campbell and Park (2014) found a marginally significant association between using mobile internet on their cell phone and adolescents' sending of sexting images or videos. They also found significant relationships between having contact with peers over the cell phone and engagement in sexting behaviors.

\section{The Current Study}

The results of previous research on the associations between sexting and risk behaviors have been muddled by the use of broad definitions of sexting behavior, the use of composite measures to assess risk behaviors, and by not accounting for contextual dynamics in which sexting takes place. With respect to the latter, there are many contexts that could be considered when taking into account the associations between sexting and risk behaviors. The goal of the current study is to investigate the distinct associations between sexting, defined herein as the sending of self-made sexually explicit images, and risk behaviors while taking into account whether they were sent within or outside of a romantic relationship. The main hypothesis is that fewer associations will exist between risk behaviors and sexting within a romantic relationship relative to sexts sent outside of a romantic relationship.

\section{Methods}

\section{Sample and Procedures}

Participants in this study were drawn from the Teen Digital Dating Study conducted from March to May 2015, in which 1235 students from 7 secondary schools in the Dutchspeaking community of Belgium were enrolled. From every school, all classes from the last two years of secondary education participated. In one vocational school, classes from the additional seventh year of vocational education were also enrolled. Because some students failed to complete the questionnaire adequately, the final dataset contained information on 1187 students between 16 and 22 years old. Students received an information letter describing the purpose of the study and the survey. The participants were assured that their answers would remain anonymous and that they could skip questions or withdraw their 
participation at any time. The contact information of the researchers was included in the information letter in case that the respondents would have additional questions or would like to be informed about the results of the study. The letter also contained the addresses of two non-profit organizations that provide hotlines where teenagers can get free information and advice about issues surrounding internet use, romantic relationships, and sexuality. To enhance the feelings of privacy, students were asked to return their completed survey in a sealed envelope. The written consent of the schools' principals was obtained and the students provided informed assent. The study's protocol and the consent procedures were approved by the Ethical Committee of the University of Antwerp.

\section{Measures}

The questionnaire focused on adolescents' sexting and the use of digital media within romantic relationships. The items concerning substance use, sexual behavior, physical violence and delinquency were adapted from the 2015 Youth Risk Behavior Survey (Centers for Disease Control and Prevention 2015).

\section{Adolescent sexting behavior}

Sexting behavior was measured with two single-item questions. The first question assessed sexting within the context of a romantic relationship. Respondents who had indicated that they were in a romantic relationship $(n=466 ; 39.3 \%)$ were asked how often they had sent a "sexually explicit picture (naked or half-naked)" of themselves to their current romantic partner through the internet or their mobile phone in the six months prior to the study, on a scale ranging from $0=$ never to $4=$ very often. The second question, assessing sexting outside of a romantic relationship, was constructed by replacing "romantic partner" with "someone else than a romantic partner" and was asked to all respondents.

\section{Smoking}

Having ever tried a cigarette The respondents were asked whether they "had ever tried a cigarette, even one or two puffs" (yes/no) ( $n_{\text {yes }}=640 ; 54.1 \%$ ).

Amount of cigarettes used in the past 30 days If the respondents provided an affirmative answer on the question about whether they had ever tried a cigarette, the amount of days that they had smoked in the 30 days prior to the study (the frequency of smoking) was also assessed, using a 7point scale $(0=0$ day; $1=1$ day; $2=2$ to 5 days; $3=6$ to 9 days; $4=10$ to 19 days; $5=20$ to 29 days; $6=$ All 30 days $)(M=1.81 ; S D=2.22)$.

\section{Alcohol use}

Having ever tried alcohol Respondents were asked if they had "ever tried alcohol" (yes/no) $\left(n_{\text {yes }}=1082 ; 91.2 \%\right)$. The following examples of alcoholic products were provided to the respondents "beer, wine, sparkling wine, gin, cocktails, gin-tonic."

Age first tried alcohol If the respondents endorsed the above question, they were also asked about the age at which they had their first drink (i.e., more than just a taste or a sip) on a scale of $1=8$ years old or younger to $6=17$ years old or older $(M=4.41 ; S D=0.84)$.

Amount of days alcohol consumed in the past 30 days Respondents who had tried alcohol were also asked about the amount of days they had drunk at least one glass during the past 30 days, using a 7-point scale $(0=0$ day; 1 $=1$ day; $2=2$ to 5 days; $3=6$ to 9 days; $4=10$ to 19 days; $5=20$ to 29 days; $6=$ All 30 days $)(M=1.92 ; S D=1.11)$.

Heavy episodic drinking Respondents who had tried alcohol were asked how many days they had engaged in heavy episodic drinking in the 30 days prior to the survey (defined as consuming more than 5 drinks of alcohol in a row within a couple of hours), on a 7-point scale ( $0=0$ days; $1=1$ day; 2 $=2$ days; $3=3$ to 5 days; $4=6$ to 9 days $; 5=10$ to 19 days; $6=20$ or more days $)(M=1.19 ; S D=1.35)$.

\section{Marihuana use}

Ever tried marihuana Respondents were asked if they had ever tried cannabis/marihuana/pot (yes/no) $\left(n_{\mathrm{yes}}=408\right.$; $34.4 \%)$.

Amount of times marihuana consumed in the past 30 days If the respondents had ever tried marijuana, they were also asked how often they used marijuana in the 30 days prior to the survey, on a 7 -point scale $(0=0$ times; $1=1$ time; $2=2$ to 5 times; $3=6$ to 9 times; $4=10$ to 19 times; $5=20$ to 39 times; $6=40$ times or more $)(M=1.31$; $S D=1.68)$.

\section{Sexual behavior and sexual risk behavior}

Ever had sexual contact Respondents were asked whether they ever had sexual contact (yes/no) $\left(n_{\mathrm{yes}}=691 ; 59.1 \%\right)$.

Age of first sexual contact Respondents who have had sexual contact were asked about the age during which they had sexual contact for the first time on a scale from $1=11$ years old or younger to $7=17$ years or older $(M=5.37$; $S D=1.16)$. 
Amount of sexual partners Sexually active respondents were also asked about the number of sexual partners during their lifetime ranging on a scale from $1=1$ person to $6=6$ or more people $(M=2.26 ; S D=1.50)$.

Use of alcohol or drugs before last sexual intercourse Sexually active respondents were asked whether they had used alcohol or drugs at the last time they had sexual intercourse (yes/no) $\left(n_{\text {yes }}=80 ; 11.6 \%\right)$.

Unsafe sexual intercourse Sexually active respondents were asked whether they had unsafe sex at the last sexual intercourse (e.g., not using protection when this was necessary) (yes/no) $\left(n_{\text {yes }}=187 ; 27.1 \%\right)$.

\section{Deviant behaviors}

Involvement in physical fights To measure involvement in physical fights, participants were asked to indicate on a 8point scale "how often they had been involved in a fight" in the six months prior to the study $(0=0$ times; $1=1$ time; 2 $=2$ or 3 times; $3=4$ or 5 times $; 4=6$ or 7 times $; 5=8$ or 9 times; $6=10$ or 11 times; $7=12$ or more times $)(M=0.19$; $S D=0.71)$. Because participants rarely endorsed this behavior, this item was recoded into a dichotomous variable with $0=$ not having engaged in the behavior and $1=$ having engaged in the behavior $(n=128 ; 10.8 \%$ having engaged in this behavior).

Vandalism Vandalism was defined as "consciously damaging someone else's property (think about graffiti spraying, damaging garbage cans, lampposts, benches or other street furniture...)". Participants indicated how often they had engaged in this behavior on a 4-point scale $(0=0$ times; $1=1$ time; $2=2$ to 3 times; $3=4$ or more times $)(M$ $=0.13 ; S D=0.47)$. As with fighting, we recoded vandalism into a dichotomous variable $\left(n_{\mathrm{yes}}=106 ; 8.9 \%\right.$ having engaged in this behavior).

\section{Bullying victimization}

Respondents were asked whether they had been "bullied in real life" in the six months prior to the survey on a scale from $0=$ never to $4=$ very often $(M=0.26 ; S D=0.60)$. In line with previous conceptualizations (Olweus 1999), bullying was defined in the survey as "Intentionally hurting or causing damage to someone that you know. People who bully, say more than once hurtful things. They have the intent to make others feel bad. Who gets bullied has difficulties to defend himself. It is not considered bullying if friends tease each other or if they are arguing with each other". Bullying was recoded into a dichotomous variable ( $n_{\text {yes }}=220 ; 18.5 \%$ reported bullying victimization).

\section{Cyberbullying victimization}

To measure cyberbullying, respondents were asked whether they had been bullied by someone through the internet or the mobile phone) $(M=0.12 ; S D=0.42)$ in the six months prior to the survey on a 5-point scale anchored by $0=$ never and $4=$ very often. Cyberbullying victimization was also recoded into a dichotomous variable $\left(n_{\mathrm{yes}}=107 ; 9.0 \%\right.$ reported cyberbully victimization).

\section{Control variables}

Gender Participants indicated whether they were male or female $(61.3 \%$ female, $n=728)$.

Age Age was derived by subtracting the participants' selfreported birth year from the year in which the study was conducted $(M=17.82$ years; $S D=0.88)$.

Sexual orientation Sexual orientation was measured by letting participants indicate whether they identified as predominantly heterosexual, equally heterosexual and homosexual, or predominantly homosexual $(n=1136 ; 95.9 \%$ identifying as predominantly heterosexual; $n=48 ; 4.1 \%$ identifying as bi- or predominantly homosexual).

Living arrangement Participants were asked to indicate their living arrangement from a list of 7 options $(0=I$ live with my mother and father; $1=$ I live with my father and his new partner; $2=$ I live with my mother and her new partner; $3=$ I live with my mother; $4=$ I live with my father; 5 $=I$ alternate between living with my father and mother; 6 =other). Living arrangement was recoded into 1) living with both parents $(n=803,67.7 \%)$ and 2$)$ other type of living situation $(n=383,32.3 \%)$.

Smartphone ownership Participants were asked to indicate whether they owned a smartphone, defined as "a phone with which you can surf the internet" (yes/no) $(n=1091 ; 91.8 \%$ owns a smartphone).

Mobile data plan Participants were asked whether they had a cell phone plan that allowed them to use the internet ( $3 \mathrm{G}$ or $4 \mathrm{G})(\mathrm{yes} / \mathrm{no})(n=874 ; 73.8 \%$ had a subscription to a mobile data plan).

Amount of social networking site use Participants were asked to indicate the amount of times they visit social networking sites on average $(0=$ Never; $1=$ Monthly; $2=$ Weekly; $3=$ A couple of days per week; $4=$ Once every day; $5=2-3$ times a day; $6=4-5$ times a day; $7=6-7$ times a day; $8=$ more than 7 times a day) $(M=6.02 ; S D=$ 1.72). 
Table 1 Control variables in relationship to the dependent variables

\begin{tabular}{|c|c|c|c|c|c|c|}
\hline \multirow[b]{2}{*}{ Predictor } & \multicolumn{2}{|c|}{ Sent a sexting picture } & \multicolumn{2}{|c|}{$\begin{array}{l}\text { Sent a sexting picture within a } \\
\text { romantic relationship }\end{array}$} & \multicolumn{2}{|c|}{$\begin{array}{l}\text { Sent a sexting picture outside of a } \\
\text { romantic relationship }\end{array}$} \\
\hline & $B$ (S.E.) & $\operatorname{Exp}(B)[95 \% \mathrm{CI}]$ & $B$ (S.E.) & $\operatorname{Exp}(B)[95 \% \mathrm{CI}]$ & $B$ (S.E.) & $\operatorname{Exp}(B)[95 \% \mathrm{CI}]$ \\
\hline Constant & $-5.69(1.68)$ & $0.00 * * *$ & $-4.97(2.82)$ & 0.01 & $-7.06(2.63)$ & $0.00 *$ \\
\hline Gender (female) & $0.05(0.16)$ & $1.05[0.76-1.45]$ & $-0.08(0.30)$ & $0.92[0.51-1.64]$ & $-0.11(0.25)$ & $0.90[0.55-1.46]$ \\
\hline Age & $0.01(0.09)$ & $1.01[0.85-1.20]$ & $-0.17(0.14)$ & $0.84[0.64-1.12]$ & $0.04(0.14)$ & $1.04[0.79-1.36]$ \\
\hline Sexual orientation & $1.15(0.33)$ & $3.14[1.65-6.00]^{* * *}$ & $1.32(0.62)$ & $3.73[1.01-12.7]^{*}$ & $1.21(0.44)$ & $3.37[1.43-7.96]^{* *}$ \\
\hline Living situation & $0.05(0.17)$ & $1.05[0.76-1.46]$ & $-0.46(0.28)$ & $0.63[0.37-1.09]$ & $0.26(0.25)$ & $1.30[0.79-2.15]$ \\
\hline Smartphone ownership & $0.92(0.49)$ & $2.52[0.96-6.64]$ & $0.89(0.82)$ & $2.44[0.49-12.11]$ & $0.60(0.65)$ & $1.82[0.51-6.46]$ \\
\hline Mobile data plan & $0.33(0.22)$ & $1.39[0.91-2.12]$ & $-0.43(0.36)$ & $0.65[0.32-1.32]$ & $0.37(0.32)$ & $1.45[0.77-2.72]$ \\
\hline SNS use & $0.26(0.05)$ & $1.29[1.16-1.44]^{* * *}$ & $0.20(0.09)$ & $1.22[1.03-1.45]^{*}$ & $0.36(0.09)$ & $1.43[1.21-1.70]^{* * *}$ \\
\hline $\begin{array}{l}\text { Length of the romantic } \\
\text { relationship }\end{array}$ & & & $0.82(0.19)$ & $2.28[1.56-3.33]^{* * *}$ & & \\
\hline
\end{tabular}

Length of the romantic relationship For students who indicated that they were in a romantic relationship $(n=466$; $39.3 \%$ ), the length of the relationship was obtained and used as a control variable within the analyses focusing on sexting within a romantic relationship. Romantic relationship length was measured on a 6 -point scale $(0=$ less than a week; $1=$ 1-2 weeks; 2=2-4 weeks; 3=1-3 months; $4=3-$ 6 months; $5=$ more than 6 months $)(M=4.22 ; S D=1.20)$. The relationships between the control variables and the dependent variables are displayed in Table 1.

\section{Statistical Analysis}

Data were analyzed using SPSS for Windows v24.0 (IBM Corp., Armonk, NY). List wise deletion was used for our analyses. Because we used a more strict definition of sexting behavior and a wider range of risk behaviors than previous research, we first assess the associations between risk behaviors, health risk behaviors, and sexting among adolescents who have and have not engaged in this behavior using logistic regressions. This approach allows us to extend previous studies, which were limited by the use of composite measures for sexting and risk behaviors. A sum score was made of the variables that assessed engagement in sexting within and outside of a romantic relationship ( $n$ $=221 ; 18.7 \%$ had engaged in sexting) and was used as the dependent variable in the logistic regressions. The risk behaviors were treated as independent variables. We used multiple tests for each independent variable. The odds ratios, adjusted (aOR) for the control variables, are reported in Table 2.

In a second step, we conducted the same analyses distinguishing relational contexts of sexting by (1) testing the model for sexting within a romantic relationship among participants who indicated being in a romantic relationship (see Tables 3) and (2) testing the same model for sexting outside of a romantic relationship among those indicated not being in a romantic relationship (see Table 4). All reported odds ratios are adjusted (aOR) for the control variables. Note that it is possible that students have a romantic relationship and also have engaged in sexting outside of the romantic relationship. It would have been interesting to consider this as a third category and explore possible associations, however, this group was too small ( $n$ $=21$ ) for statistical testing. In order to avoid including these participants in both analyses they were removed from this and subsequent analyses.

In a final step, we compared the types of risk behaviors between (1) those who had engaged in sexting with their romantic partner and who indicated that they were in a romantic relationship at the time of the survey and (2) those who had engaged in sexting outside a romantic relationship and indicated that they were not in a romantic relationship at the time of the survey. A chi-square test was used for dichotomous variables and a $t$-test was used for ordinal variables to investigate significant differences between the two groups. A Fisher's exact test was used when the sample size was too small to perform a chi-square test. Results are presented in Table 5.

\section{Results}

\section{Control Variables Associated with Sexting}

As presented in Table 1, results of the logistic regression analyses for sexting, regardless of the type of romantic relationship, show that sexual orientation (OR: 3.14; $95 \%$ confidence interval CI: $1.65-6.00)$ and the amount of social networking site use (OR: 1.29; 95\% CI: 1.16-1.44) were significantly associated with sexting behavior. Among the control variables for sexting with a romantic partner, sexual 
Table 2 Associations between substance use, sexual behavior, sexual risk behavior, deviant behaviors, and bullying victimization for youth who engage in sexting

Did not sent a sexting $\quad$ Sent a sexting picture $\quad$ aOR $[95 \% \mathrm{CI}]$
picture

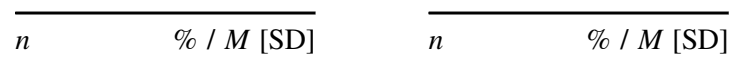

Ever tried a cigarette

No

Yes

Amount of cigarettes (past 30 days)

Ever tried alcohol

No

Yes

Age first tried alcohol

Amount of days alcohol consumed (past 30 days)

Heavy episodic drinking (past 30 days)

Ever tried marihuana

No

Amount of times marihuana use (past 30 days)

Ever had sexual contact

No
Yes

Age of first sexual contact

Amount of sexual partners

Alcohol/drug use before sex

No

Yes

Had unsafe sex

No

Yes

Amount of times involved in a fight

$$
\text { No }
$$

Yes

Amount of times involved in vandalism

$$
\text { No }
$$$$
\text { Yes }
$$

Victim of cyberbullying

$$
\begin{aligned}
& \text { No } \\
& \text { Yes }
\end{aligned}
$$

Victim of bullying

No
Yes

\section{7}

445

445

90

822

807

807

807

627

627
285

285

440

472

462

462

409

53

348

114

$\begin{array}{ll}818 & 89.7 \% \\ 94 & 10.3 \%\end{array}$

836

76

840

72

$7.9 \%$

760

152
$91.7 \%$

$8.3 \%$

$92.1 \%$

$51.2 \%$

$48.8 \%$

$9.9 \%$

$90.1 \%$

4.45 [0.84]

1.88 [1.11]

1.11 [1.32]

$68.8 \%$

$31.3 \%$

1.23 [1.66]

$48.2 \%$

$51.8 \%$

5.44 [1.13]

2.18 [1.43]

$88.5 \%$

$11.5 \%$

$75.3 \%$

$24.7 \%$

$83.3 \%$

$16.7 \%$

\section{6}

156

156

9

203

200

200

200

111

101

101

21

191

186

186

165

21

124

62

182

30

186

26

182

30

159

53

$26.4 \%$
$73.6 \%$
$1.62[2.10]$

$4.2 \%$

$95.8 \%$

4.28 [0.80]

2.16 [1.12]

1.45 [1.43]

$52.4 \%$

$47.6 \%$

1.43 [1.68]

$9.9 \%$

$90.1 \%$

5.12 [1.21]

2.58 [1.67]

$88.7 \%$

$11.3 \%$

$66.7 \%$

$33.3 \%$

$85.8 \%$

$14.2 \%$

$87.7 \%$

$12.3 \%$

$85.8 \%$

$14.2 \%$

$75.0 \%$

$25.0 \%$
$1.00(\mathrm{RG})$

$2.71[1.92-3.84]^{* * *}$

0.96 [0.88-1.05]

1.00 (RG)

1.92 [0.92-3.99]

0.79 [0.65-0.96]*

$1.26[1.08-1.46]^{* *}$

$1.22[1.08-1.37]^{* * *}$

1.00 (RG)

$2.09[1.50-2.90]^{* * *}$

1.18 [1.02-1.37]*

The models are adjusted for gender, age, sexual orientation, living arrangement, smartphone ownership, amount of social networking site use, and subscription to a mobile data plan

$C I$ confidence Interval, $R G$ reference group, $a O R$ odds ratio adjusted for gender, age, sexual orientation, living arrangement, smartphone ownership, amount of social networking site use, and subscription to a mobile data plan

$* p \leq 0.05$; ** $p \leq 0.01$; *** $p \leq 0.001$ 
Table 3 Associations between substance use, sexual behavior, sexual risk behavior, deviant behaviors, and bullying victimization for youth who engage in sexting within a romantic relationship and who reported being in a romantic relationship at the time of the study

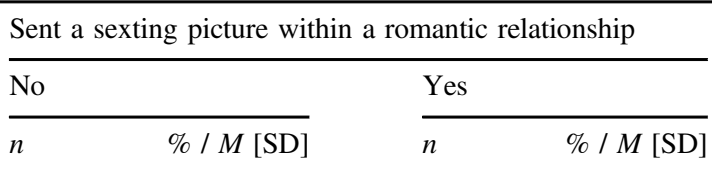

aOR $[95 \% \mathrm{CI}]$

Ever tried a cigarette

No

Yes

Amount of cigarettes (past 30 days)

Ever tried alcohol

No

Yes

Age first tried alcohol

Amount of days alcohol consumed (past

30 days)

Heavy episodic drinking (past 30 days)

Ever tried marihuana

No

Yes

Amount of times marihuana use (past 30 days)

Ever had sexual contact

No

Age of first sexual contact

Amount of sexual partners

Alcohol/drug use before sex

No

Yes

Had unsafe sex

No

Yes

Involved in a fight

No

Yes

Involved in vandalism

No

Yes

Victim of cyberbullying

drinking (past 30 days)
Age of first sexual contact
Amount of sexual partners
Acohol/drug use before sex

No

Yes

Victim of bullying

No

Yes

\section{0}

206

206

14

322

319

319

319

207

129

129

\section{4}

563

296

296

279

17

215

81

302

34

303

33

306

30

273

63
$90.2 \%$

$38.7 \%$

$61.3 \%$

2.01 [2.32]

$4.2 \%$

$95.8 \%$

4.46 [0.87]

1.95 [1.11]

1.10 [1.34]

$61.6 \%$

$38.4 \%$

1.24 [1.57]

$10.1 \%$

$89.9 \%$

5.48 [1.11]

2.18 [1.42]

$94.3 \%$

$5.7 \%$

$72.6 \%$

$27.4 \%$

$89.9 \%$

$10.1 \%$

$9.8 \%$

$91.1 \%$

$8.9 \%$

$81.3 \%$

$18.8 \%$
24

60

60

7

77

75

75

75

46

38

38

\section{2}

82

81

81

75

6

53

28

72

12

76

8

72

12

62

22
$28.6 \%$

$71.4 \%$

1.77 [2.42]

$8.3 \%$

$91.7 \%$

4.33 [0.81]

2.15 [1.15]

1.33 [1.43]

$54.8 \%$

$45.2 \%$

1.66 [1.77]

$2.4 \%$

$97.6 \%$

5.25 [1.13]

2.20 [1.63]

$92.6 \%$

$7.4 \%$

1.00 (RG)

1.59 [0.55-4.61]

$65.4 \%$

$34.6 \%$

1.00 (RG)

1.45 [0.83-2.52]

$85.7 \%$

1.00 (RG)

$14.3 \%$

1.46 [0.66-3.26]

$90.5 \%$

$9.5 \%$

1.00 (RG)

0.74 [0.30-1.84]

The models are adjusted for gender, age, sexual orientation, living arrangement, smartphone ownership, amount of social networking site use, subscription to a mobile data plan, and relationship length

$C I$ confidence interval, $N C$ not calculable, $R G$ reference group, $a O R$ odds ratio adjusted for gender, age, sexual orientation, living arrangement, smartphone ownership, amount of social networking site use, subscription to a mobile data plan, and relationship length

$* p \leq 0.05 ; * * \leq 0.01 ; * * * \leq 0.001$ 
Table 4 Associations between substance use, sexual behavior, sexual risk behavior, deviant behaviors, and bullying victimization for youth who engage in sexting outside of a romantic relationship and who indicated that they were not in a romantic relationship at the time of the study

$\begin{array}{ll}\frac{\text { Sent a sexting picture outside of a romantic relationship }}{\text { No }} & \frac{\text { Yes }}{n / M[\mathrm{SD}]}\end{array} \frac{\% / M[\mathrm{SD}]}{n}$

aOR $[95 \% \mathrm{CI}]$

Ever tried a cigarette

No

Yes

Amount of cigarettes (past 30 days)

Ever tried alcohol

No

Yes

Age first tried alcohol

Amount of days alcohol consumed (past 30 days)

Heavy episodic drinking (past 30 days)

Ever tried marihuana

No

Yes

Amount of times marihuana use (past 30 days)

Ever had sexual contact

$$
\begin{gathered}
\text { No } \\
\text { Yes }
\end{gathered}
$$

Age of first sexual contact

Amount of sexual partners

Alcohol/drug use before sex

No

Yes

Had unsafe sex

No

Yes

Involved in a fight

Ever tried a cigarette
No
Yes
Amount of cigarettes (past 30 days)
Ever tried alcohol
No
Yes
Age first tried alcohol
Amount of days alcohol consumed (past
days)
Heavy episodic drinking (past 30 days)
Ever tried marihuana
No
Yes
Amount of times marihuana use (past
days)
Ever had sexual contact
No
Yes
Age of first sexual contact
Amount of sexual partners
Alcohol/drug use before sex
No
Yes
Ho
No unolved in vandalism
No
Yes
No
No
No

Involved in vandalism

$$
\text { No }
$$

Yes

Victim of cyberbullying

$$
\text { Yes }
$$

\begin{tabular}{|c|c|c|c|c|}
\hline 405 & $68.1 \%$ & 17 & $20.2 \%$ & $1.00(\mathrm{RG})$ \\
\hline 190 & $31.9 \%$ & 67 & $79.8 \%$ & $8.31[4.58-15.08]^{* * *}$ \\
\hline 186 & $5.32[1.19]$ & 64 & $5.09[1.22]$ & $0.85[0.66-1.01]$ \\
\hline 186 & $2.29[1.50]$ & 64 & $2.72[1.59]$ & $1.22[1.00-1.48]^{*}$ \\
\hline 149 & $80.1 \%$ & 51 & $79.7 \%$ & $1.00(\mathrm{RG})$ \\
\hline 37 & $19.9 \%$ & 13 & $20.3 \%$ & $1.23[0.59-2.57]$ \\
\hline 141 & $75.8 \%$ & 47 & $73.4 \%$ & $1.00(\mathrm{RG})$ \\
\hline 45 & $24.2 \%$ & 17 & $26.6 \%$ & $1.20[0.61-2.36]$ \\
\hline 533 & $89.6 \%$ & 73 & $86.9 \%$ & $1.00(\mathrm{RG})$ \\
\hline 62 & $10.4 \%$ & 11 & $13.1 \%$ & $1.22[0.58-2.55]$ \\
\hline 547 & $91.9 \%$ & 75 & $89.3 \%$ & $1.00(\mathrm{RG})$ \\
\hline 48 & $8.1 \%$ & 9 & $10.7 \%$ & $1.11[0.50-2.47]$ \\
\hline 550 & $92.4 \%$ & 72 & $85.7 \%$ & $1.00(\mathrm{RG})$ \\
\hline 45 & $7.6 \%$ & 12 & $14.3 \%$ & $1.78[0.86-3.69]$ \\
\hline 501 & $84.2 \%$ & 64 & $76.2 \%$ & $1.00(\mathrm{RG})$ \\
\hline 94 & $15.8 \%$ & 20 & $23.8 \%$ & $1.42[0.79-2.55]$ \\
\hline
\end{tabular}

Victim of bullying

No
Yes

The models are adjusted for gender, age, sexual orientation, living arrangement, smartphone ownership, amount of social networking site use, and subscription to a mobile data plan

$C I$ confidence interval, $N C$ not calculable, $R G$ reference group, $a O R$ odds ratio adjusted for gender, age, sexual orientation, living arrangement, smartphone ownership, amount of social networking site use, and subscription to a mobile data plan

$* p \leq 0.05 ; * * p \leq 0.01 ; * * * p \leq 0.001$

$\begin{array}{lllll}340 & 57.1 \% & 24 & 28.6 \% & 1.00(\mathrm{RG}) \\ 255 & 42.9 \% & 60 & 71.4 \% & 3.03[1.80-5.13]^{* * *} \\ 255 & 1.68[2.15] & 60 & 1.55[1.98] & 0.96[0.83-1.12]\end{array}$

$\begin{array}{lllll}76 & 12.8 \% & 0 & 0.0 \% & 1.00(\mathrm{RG})\end{array}$

$519 \quad 87.2 \%$

$507 \quad 4.42[0.81]$

$100.0 \%$

$\mathrm{NC}$

$4.18[0.80] \quad 0.68[0.51-0.92]^{*}$

$2.24[1.14]$

$1.39[1.10-1.75]^{* *}$

507

1.14 [1.33]

83

1.60 [1.40]

$1.30[1.09-1.56]^{* *}$

$429 \quad 72.1 \%$

$27.9 \%$

$166 \quad 1.21$ [1.72]

$42 \quad 50.0 \%$

$1.00(\mathrm{RG})$

$50.0 \%$

$2.85[1.70-4.78]^{* * *}$

$42 \quad 1.31$ [1.67]

1.11 [0.89-1.39] 
Table 5 Differences in substance use, sexual behavior, sexual risk behavior, deviant behaviors, and bullying victimization between youth who engage in sexting within a romantic relationship and indicated that they were in a romantic relationship at the time of the study and youth who engage in sexting outside of a romantic relationship and who indicated that they were not in a romantic relationship at the time of study

\begin{tabular}{|c|c|c|c|}
\hline & $\begin{array}{l}\text { Sent a sexting picture within a } \\
\text { romantic relationship } n(\% / M[\mathrm{SD}]) n \\
=87\end{array}$ & $\begin{array}{l}\text { Sent a sexting picture outside of a } \\
\text { romantic relationshipn }(\% / M[\mathrm{SD}]) n= \\
113\end{array}$ & $\begin{array}{l}\chi^{2} / t \text {-value / Mann- } \\
\text { Withney U / Fisher's exact } \\
\text { test }\end{array}$ \\
\hline Ever tried a cigarette (No/Yes) & $24(28.6 \%) / 60(71.4 \%)$ & $24(28.6 \%) / 60(71.4 \%)$ & $0.000(p=1.00)^{\mathrm{a}}$ \\
\hline $\begin{array}{l}\text { Amount of cigarettes (past } \\
30 \text { days) }\end{array}$ & $60(1.77[2.42])$ & $60(1.55[1.98])$ & $0.537(p=0.592)^{\mathrm{b}}$ \\
\hline Ever tried alcohol (No/Yes) & 7 (8.3\%) / 77 (91.7\%) & $0(0.0 \%) / 84(100.0 \%)$ & $p=0.007^{\mathrm{c}}$ \\
\hline Age first tried alcohol & $75(4.33[0.81])$ & $83(4.18[0.80])$ & $1.191(p=0.236)^{\mathrm{b}}$ \\
\hline $\begin{array}{l}\text { Amount of days alcohol } \\
\text { consumed (past } 30 \text { days) }\end{array}$ & $75(2.15[1.15])$ & $83(2.24[1.14])$ & $-0.517(p=0.606)^{\mathrm{b}}$ \\
\hline Binge drinking (past 30 days) & $75(1.33[1.43])$ & $83(1.60[1.40])$ & $-1.193(p=0.235)^{\mathrm{b}}$ \\
\hline Ever tried marihuana (No/Yes) & $46(54.8 \%) / 38(45.2 \%)$ & $42(50.9 \%) / 42(49.1 \%)$ & $0.382(p=0.537)^{\mathrm{a}}$ \\
\hline $\begin{array}{l}\text { Amount of times marihuana } \\
\text { use (past } 30 \text { days) }\end{array}$ & $38(1.66[1.77])$ & $42(1.31[1.67])$ & $0.903(p=0.369)^{\mathrm{b}}$ \\
\hline $\begin{array}{l}\text { Ever had sexual contact }(\mathrm{No} / \\
\text { Yes) }\end{array}$ & $2(2.4 \%) / 82(97.6 \%)$ & $17(20.2 \%) / 67(79.8 \%)$ & $13.352(p=0.000)^{\mathrm{a}}$ \\
\hline Age of first sexual contact & $81(5.25[1.13])$ & $64(5.09[1.22])$ & $0.789(p=0.431)^{\mathrm{b}}$ \\
\hline Amount of sexual partners & $81(2.20[1.63])$ & $64(2.72[1.59])$ & $-1.933(p=0.055)^{\mathrm{b}}$ \\
\hline $\begin{array}{l}\text { Alcohol/drug use before sex } \\
\text { (No/Yes) }\end{array}$ & $75(92.6 \%) / 6(7.4 \%)$ & $51(79.7 \%) / 13(20.3 \%)$ & $5.229(p=0.022)^{\mathrm{a}}$ \\
\hline Had unsafe sex (No/Yes) & $53(65.4 \%) / 28(34.6 \%)$ & $47(73.4 \%) / 17(26.6 \%)$ & $1.071(p=0.301)^{\mathrm{a}}$ \\
\hline $\begin{array}{l}\text { Amount of times involved in a } \\
\text { fight }\end{array}$ & $72(85.7 \%) / 12(14.3 \%)$ & $73(86.9 \%) / 11(13.1 \%)$ & $0.050(p=0.822)^{\mathrm{a}}$ \\
\hline $\begin{array}{l}\text { Amount of times involved in } \\
\text { vandalism }\end{array}$ & $76(90.5 \%) / 8(9.5 \%)$ & $75(89.3 \%) / 9(10.7 \%)$ & $0.065(p=0.798)^{\mathrm{a}}$ \\
\hline Victim of cyberbullying & $72(85.7 \%) / 12(14.3 \%)$ & $72(86.1 \%) / 12(13.9 \%)$ & $0.000(p=1.00)^{\mathrm{a}}$ \\
\hline Victim of bullying & $62(73.8 \%) / 22(26.2 \%)$ & $64(76.2 \%) / 20(23.8 \%)$ & $0.127(p=0.722)^{\mathrm{a}}$ \\
\hline
\end{tabular}

orientation (OR: 3.73; 95\% CI: 1.01-12.7), social networking site (SNS) use (OR: 1.22; 95\% CI: 1.03-1.45), and length of the romantic relationship (OR: 2.28; $95 \% \mathrm{CI}$ : 1.56-3.33) were significantly associated with sexting. For the model on sexting images outside of a romantic relationship, sexual orientation (OR: 3.37; 95\% CI: 1.43-7.96) and frequency of SNS use (OR: 1.43; 95\% CI: 1.21-1.70) were significantly associated with sexting behavior. None of the other control variables were significantly related to sexting behavior in any of the three models.

\section{The Associations between Adolescent Sexting and Risk Behaviors Regardless of Relational Context}

\section{Substance use}

As shown in Table 2, youth who ever tried a cigarette were significantly more likely to have sexted than their nonsmoking counterparts (aOR: 2.71; 95\% CI: 1.92-3.84). The average cigarette consumption in the 30 days prior to the study was not significantly linked with the sending of a sexting picture (aOR: 0.96; 95\% CI: 0.88-1.05).

There was no significant association between having ever tried alcohol and sending a sext (aOR: 1.92; 95\% CI: 0.92-3.99). However, youth who had tried alcohol at a younger age were significantly more likely to have sexted (aOR: 0.79 ; 95\% CI: $0.65-0.96$ ) as were youth who had consumed alcohol in the thirty days prior to the study (aOR: 1.26; 95\% CI: 1.08-1.46) and who had engaged in heavy episodic drinking in the 30 days prior to the study (aOR: 1.22; 95\% CI: 1.08-1.37).

Respondents who had ever tried marihuana were more likely to report that they had sexted (aOR: 2.09 ; $95 \% \mathrm{CI}$ : 1.50-2.90) than those who reported never trying marihuana. Likewise, students who had recently used marihuana were more likely to have sent sexts (aOR: 1.18; 95\% CI: $1.02-1.37$ ), relative to those who had not recently used this substance. 


\section{Sexual behavior and sexual risk behavior}

Youth with a history of sexual contact were significantly more likely to have sexted (aOR: 8.71; 95\% CI: 5.33-14.23) than those with no history of sexual contact. Respondents who reported a younger age of first sexual contact (aOR: 0.81; 95\% CI: 0.69-0.94) and youth who reported a higher amount of sexual partners were significantly more likely to have engaged in sexting (aOR: 1.21; 95\% CI: 1.08-1.37). Adolescents who reported unsafe sex at their last sexual intercourse (aOR: 1.55 ; $95 \%$ CI: 1.06-2.28) were also significantly more likely to have engaged in sexting than those who did not report unsafe sex. There was no significant relationship between having used alcohol and drugs before the last sexual encounter and sending sexts (aOR: 1.12; 95\% CI: 0.64-1.95).

\section{Deviant behaviors and bullying victimization}

There were no significant links between having been involved in a fight (aOR: 1.30 ; 95\% CI: $0.81-2.09$ ) or having committed vandalism (aOR: 1.42; 95\% CI: 0.86-2.35) and sexting. However, youth who had reported victimization of bullying (aOR: 1.55; 95\% CI: 1.07-2.25) and cyberbullying (aOR: 1.69; 95\% CI: 1.04-2.73) were significantly more likely to have sexted than those who did not report (cyber)bullying victimization.

\section{The Associations between Sexting among Adolescents in a Romantic Relationship and Risk Behaviors}

\section{Substance use}

As reported in Table 3, adolescents with a history of cigarette use were more likely to have sexted their romantic partners (aOR: 1.92; 95\% CI: 1.09-3.38) than their nonsmoking counterparts. However, significant associations did not emerge between the amount of cigarette use in the 30 days prior to the survey and engagement in sexting within a romantic relationship (aOR: $0.98 ; 95 \%$ CI: $0.85-1.12$ ).

There were no relationships between sexting within a romantic relationship and having ever tried alcohol (aOR: 0.49 ; 95\% CI: 0.18-1.36), having consumed alcohol on more days in the month prior to the study (aOR: $1.25 ; 95 \%$ CI: 0.98-1.59), the age of having first tried alcohol (aOR: 0.88 ; 95\% CI: 0.64-1.20), or heavy episodic drinking (aOR: 1.17 ; 95\% CI: $0.96-1.43$ ).

Youth who ever tried marihuana (aOR: $1.28 ; 95 \%$ CI: $0.75-2.18$ ) were not more likely to have sexted with a romantic partner than those who had not tried marihuana. There was, however, a significant relationship between reported marihuana use in the 30 days prior to the study and having engaged in sexting with a romantic partner (aOR: 1.36; 95\% CI: $1.07-1.74$ ).

\section{Sexual behavior and sexual risk behavior}

There were no significant associations found between sexting and any of the assessed sexual behaviors, including sexual risk behaviors.

\section{Deviant behaviors and bullying victimization}

There were no significant associations between sexting and having been involved in fights (aOR: 1.46; 95\% CI: 0.66-3.26), vandalism (aOR: 0.74 ; $95 \% \mathrm{CI}: 0.30-1.84$ ), or being victimized by bullying (aOR: $1.65 ; 95 \%$ CI: 0.91-3.00) or cyberbullying (aOR: $1.81 ; 95 \%$ CI: 0.83-3.94).

\section{The Associations between Sexting and Risk Behaviors among Adolescents not in a Romantic Relationship}

\section{Substance use}

As shown in Table 4, single adolescents who had ever tried a cigarette were more likely to have sexted someone who was not a romantic partner (aOR: 3.03 ; 95\% CI: $1.80-5.13$ ) relative to their non-smoking counterparts. However, there were no significant associations between the amount of cigarette use in the 30 days prior to the survey and sexting outside of a romantic relationship (aOR: 0.96; 95\% CI: 0.83-1.12).

Single adolescents who drank alcohol at a younger age were more likely to have sexted a non-romantic partner (aOR: 0.68; 95\% CI: 0.51-0.92) than their non-drinking counterparts. Single respondents who engaged in heavy episodic drinking and who consumed alcohol on more days in the month prior to the study were more likely to engage in sexting, relative to those who did not participate in heavy episodic drinking (aOR: 1.30; 95\% CI: 1.09-1.56) and drank alcohol on less days (aOR: 1.39; 95\% CI: 1.01-1.75), respectively.

Single youth who reported a history of marihuana use were more likely to have sexted than those who had not tried marihuana (aOR: 2.85; 95\% CI: 1.70-4.78). No significant association emerged between the frequency of marihuana use and sexting outside of a romantic relationship (aOR: 1.11; 95\% CI: 0.89-1.39).

\section{Sexual behavior and sexual risk behavior}

Single youth with a history of sexual contact (aOR: 8.31; 95\% CI: 4.58-15.08) or who reported more lifetime sexual 
partners (aOR: 1.22; 95\% CI: 1.00-1.48) were more likely to have sexted. No significant associations emerged between sexting and age of first sexual contact, having used alcohol or drugs before having sex, or having unsafe sex.

\section{Deviant behaviors and bullying victimization}

No significant associations emerged between sexting outside of a romantic relationship and being involved in fights (aOR: 1.22 ; 95\% CI: 0.58-2.55), vandalism (aOR: 1.11; 95\% CI: 0.50-2.47), bullying victimization (aOR: 1.42; 95\% CI: 0.79-2.55), and cyberbullying victimization (aOR: 1.78 ; 95\% CI: $0.86-3.69)$.

\section{Differences in Risk Behaviors between Adolescents Who Sexted Within a Romantic Relationship and Adolescents Who Sexted Outside of a Romantic Relationship}

\section{Substance use}

As reported in Table 5, adolescents who sexted their romantic partner did not differ significantly from single adolescents who had sexted someone other than a romantic partner with respect to having ever tried a cigarette $\left(\chi^{2}(1)=\right.$ $0.00, p=1.00)$, frequency of recent cigarette use $(t$ $(113.555)=0.537, p=0.59)$, having ever tried marihuana $\left(\chi^{2}(1)=0.38, p=0.54\right)$, frequency of recent marihuana use $(t(78)=0.90, p=0.37)$, average age at which they had first tried alcohol $(t(156)=1.19, p=0.24)$, the frequency of recent alcohol use $(t(156)=-0.52, p=0.61)$, and the frequency of episodic heavy drinking $(t(156)=-1.19, p=$ $0.23)$.

\section{Sexual behavior and sexual risk behavior}

Youth who sexted a romantic partner were more likely to report a history of sexual contact compared to nonromantically involved youth who sexted outside of a romantic relationship $\left(\chi^{2}(1)=13.35, p=0.00\right)$. Single adolescents who were sexually active and who sexted had on average more sexual partners than those who engaged in sexting within a romantic relationship. This difference was, however, only marginally significant $(t(143)=-1.93, p=$ $0.055)$.

Single youth who sexted outside of a romantic relationship were more likely to have used alcohol or drugs prior to their most recent sexual encounter $\left(\chi^{2}(1)=5.23 ; p=0.02\right)$ compared to youth who sexted within a romantic relationship. There were no group differences with regards to the age of first sexual contact $(t(143)=0.79, p=0.43)$ and whether respondents had used protection during their last sexual encounter $\left(\chi^{2}(1)=1.07, p=0.30\right)$.

\section{Conduct problems and bullying victimization}

No significant between group differences emerged with regard to sexting, involvement in fights $\chi^{2}(1)=0.05, p=$ $0.82)$, vandalism $\left(\chi^{2}(1)=0.06, p=0.80\right)$, and bullying $\left(\left(\chi^{2}\right.\right.$ $(1)=0.13, p=0.72)$ or cyberbullying $\left(\chi^{2}(1)=0.00, p=\right.$ 1.00) victimization.

\section{Discussion}

During puberty, teenagers start to view and understand their bodies in sexual ways. For some adolescents, sexting can be a part of their developmental process and their needs for sexual experimentation (Thomas 2018). Adolescent sexting is a risk behavior, as the images could be forwarded or shown to others who were never intended to be the receiver. This could lead to bullying and reputational damage (Temple 2015). Sexting, the sending of sexually explicit pictures has gained significant research attention over the past years (Van Ouytsel et al. 2018, ab). One of the main areas in the field is how sexting relates to other risky behavior (Van Ouytsel et al. 2015). The extant research examining this link have been largely equivocal, perhaps owing to the fact that the studies did not consider contextual determinants. Indeed, following the Differential Susceptibility to Media Effects Model (Valkenburg and Peter 2013), which states that some individuals are more susceptible to media effects than others and use media in different ways, contextual differences for individuals' sexting behaviors could be expected. Accounting for the different social dynamics in which sexting takes place might be important as they could have an impact on how sexting relates to known risk behaviors. To begin addressing this knowledge gap, we investigated whether the link between sexting and known risk behaviors differed based on relationship context.

Existing research on the link between sexting and risk behaviors has also been limited by the inconsistent ways sexting has been defined (Englander and McCoy 2018). For the current study, we defined sexting as the sending of selfmade sexually explicit pictures rather than the broad conceptualization of sending sexually explicit text messages and pictures. By not mixing behaviors with a varying degree of risk (i.e., sexually explicit text messages and images) as part of our outcome measure, we were able to better address the specific associations between the sending of self-made sexually explicit images and risk behaviors. Finally, as opposed to previous studies which often used composite scores for deviant behaviors, incorporating very diverse behaviors to assess the links between sexting and other types of problem behaviors, we focused on the associations between adolescents' engagement in sexting and 
specific, well-defined problems and health-risk behaviors (i.e., smoking, alcohol use, including problematic alcohol use, marijuana use, and sexual risk behaviors).

We found that a sizeable minority of our respondents $(n$ $=221 ; 18.6 \%$ ) had engaged in sexting, with $7.3 \%$ of the total sample having done so within the context of a romantic relationship, $9.5 \%$ outside of the context of a romantic relationship and $1.8 \%$ having engaged in sexting in both relational contexts. Our prevalence rates are in line with those by Wood et al. (2015) who found, in a cross-cultural study in several European countries, that the prevalence of sending sexually explicit images ranged between 10.0 and $38.0 \%$. They are also similar to the prevalence published in a recent meta-analysis, which found that $14.8 \%$ of youth worldwide had engaged in sexting (Madigan et al. 2018). In the remainder of the discussion, we first focus on the findings between general sexting (regardless of context) followed by the findings of separate analyses between sexting inside and outside the context of a romantic relationship.

\section{General Adolescent Sexting and Substance Use}

In line with problem behavior theory (Jessor 2014), which posits that risk behaviors share similar antecedents, we found multiple associations between risk behaviors and sexting. Similar to Temple and colleagues' (2014) study that found associations between sexting and a composite measure of lifetime substance use, our findings indicate that youth who have ever tried cigarettes or marijuana were more likely to sext than those who had not tried these substances. This finding is in line with a study by Dake et al. (2012) who found associations between substance use (marijuana, cigarette and alcohol use) and a broadly defined measure of sexting behavior (i.e., sending of sexually explicit text messages and pictures). As opposed to Dake et al. (2012) who used a broad definition of sexting, we did not find a significant relationship between smoking cigarettes in the past 30 days and engagement in sexting.

We also found that youth who reported heavy episodic drinking, consumed alcohol on more days, and had tried alcohol at a younger age were more likely to sext that their non-substance using counterparts. This finding might be worrisome as consuming alcohol could lower adolescents' inhibitions and their ability to critically reflect on the risks and consequences associated with sexting (Van Ouytsel et al. 2015; Temple et al. 2014). Future longitudinal studies should further investigate extent to which adolescents' engagement in sexting occurs after alcohol consumption and, if so, whether it is more likely to lead to negative consequences such as the nonconsensual distribution of sexted pictures. The results further underscore the need for sexting prevention to be embedded in prevention efforts on healthy relationships that also target substance use prevention (Temple and Lu 2018).

\section{General Adolescent Sexting, Sexual Behavior, and Sexual Risk Behavior}

Similar to previous studies (Rice et al. 2018; Temple and Choi 2014; Ybarra and Mitchell 2014), we found that adolescents who had more previous sexual experiences were more likely to engage in sexting. Likewise, adolescents who had their first sexual contact at a younger age or had more sexual partners in their lifetime were more likely to have sent a sext. Similarly to findings of Dake et al. (2012) who found an association between non-use of contraceptives and a broad measure of sexting, we found that students who reported a history of unsafe intercourse at their last sexual encounter were more likely to report sexting. However, it might be that these findings would not hold when investigated longitudinally, as research by Temple and Choi (2014) found that sending self-made sexually explicit pictures was linked with sexual behaviors but not with sexual risk behaviors in the following year. More longitudinal research with more diverse samples is therefore warranted. The results of our study underscore the need for conversations about sexting and educational efforts to focus on the role of sexting within sexual behaviors and to discuss safe sexting behaviors within sexual and relationship education.

\section{General Adolescent Sexting, Deviant Behaviors and Bullying Victimization}

That youth who reported being a victim of in-person bullying and cyberbullying were more likely to engage in sexting is consistent with research showing a link between cyberbullying victimization and engagement in risky internet behavior (Agaston et al. 2012; Walrave and Heirman 2011). It is also in line with cross-sectional research that found assocations between broad conceptualizations of sexting, which included the sending of sexually explicit text messages, and bullying (Dake et al. 2012; West et al. 2014). Longitudinal research is warranted to determine whether victimization of bullying and cyberbullying could lead to sexting or vice versa, as victims may be under pressure to engage in sexting, or sexted images are further distributed and could lead to (cyber)bullying victimization. When talking to adolescents about sexting, practitioners could screen for (cyber)bullying victimization and vice versa, and discuss internet safety along with ways to avoid or safely engage in sexting behavior.

Contrary to Lee and colleagues (2016), who established associations between sexting and a general broad measure of deviant behaviors (ranging from smoking to having sex 
for money), our study did not find that youth who engaged in sexting were more involved in fighting or vandalism than those who did not sext. This latter finding further contributes to the notion that sexting may better be understood as a risk marker as opposed to a deviant behavior (Cooper et al. 2016; Kosenko et al. 2017).

\section{Sexting a Romantic Partner Within a Relationship}

We found that sexting was only minimally associated with risk behaviors within the context of a romantic relationship. Indeed, we only found sexting to be related to having ever tried a cigarette and recent use of marijuana. Thus, at least within the context of a romantic relationship, sexting does not appear to be a strong indicator of engagement in risk behaviors. Qualitative research indicates that youth who engage in sexting within a romantic relationship do so primarily to flirt and sustain intimacy with their partner; perhaps a form of intimate self-disclosure within romantic relationships (Van Ouytsel et al. 2017). Consistent with research among adult samples (McDaniel and Drouin 2015), sexting within adolescents' romantic relationships may be viewed as a normative behavior. In addition, sexting within a romantic relationship could be perceived as less risky which could further explain the absence of associations with risk behaviors in this context (Van Ouytsel et al. 2018b).

\section{Sexting Outside of a Romantic Relationship}

Among adolescents not involved with a current partner, we identified several associations between sexting and the use of specific substances, including lifetime substance use and recent heavy episodic drinking. These findings are consistent with research among adults in which problematic alcohol use was indirectly related to sexual hook-ups through sexting (Dir et al. 2013). Additional research is warranted to examine whether these associations also exist among adolescents. The findings also emphasize again the need for healthy relationship education to integrate messages about substance use and to focus on multiple risk behaviors simultaneously (Wolfe et al. 2009).

Sexually active single youth were more likely to sext than were non-sexually active single youth. Sexters in this group, relative to their non-sexting counterparts, also reported more lifetime sexual partners. The link between sexting and sexual behaviors in this and multiple other studies indicates that these online and offline behaviors may co-occur (Kosenko et al. 2017). Notably, no significant relationships between sexting and sexual risk behaviors were found.

Prior research that did not take into account the context in which sexting takes place found that adolescents who engaged in sexting were more likely to score high on impulsivity (Temple et al. 2014) and sensation seeking (Van Ouytsel et al. 2014). Given that sexting outside of a romantic relationship could be perceived as a more risky behavior, youth who engage in this form of sexting might also be more likely to engage in offline risk behavior. Future research could investigate the personality characteristics of youth who engage in sexting within and outside of a romantic relationship. From a Differential Susceptibility to Media Effects model, we could expect that youth who seek out thrill and risky behavior, may have a heightened likelihood of sexting outside of a romantic relationship (Van Ouytsel et al. 2017).

Future studies could also more deeply investigate how peer pressure and susceptibility to peer pressure might be related to associations between sexting outside of a romantic relationship and engagement in sexting among single adolescents. Previous research found that youth often perceived pressure when engaging in sexting, either from peers (Ringrose et al. 2012) or from their sexting partners (Drouin et al. 2015; Englander and McCoy 2017). One study found that one of the primary sources of sexting pressure was found among girls who were not yet in an established romantic relationship, but who were engaging in sexting with a potential romantic partner (Englander 2015). Peer pressure also plays an important role in adolescents' engagement in other risk behaviors, such as substance use (Onrust et al. 2016).

From a lifestyle-routine activities theory perspective the associations with substance use measures and engagement in sexting outside of a romantic relationship might be worrisome, as the theory would predict youth who engage in a risky lifestyle, are more likely to become a victim of a crime or abuse (Gover 2004). Prior research has found that youth who engage in risk behaviors, such as alcohol use, are more likely to become victims of both offline (Gover 2004) and online forms of dating abuse (Melander and Hughes 2018). Future research is needed to investigate whether single youth who engage in offline risk behaviors might also be at heightened risk to experience abusive forms of sexting such as having their sexting images forwarded or being pressured into engaging in sexting.

\section{Does Relationship Context Matter?}

Contrary to our overall hypothesis, when directly comparing both contexts, our analyses revealed only minor differences between sexting inside and outside of a relationship. The only meaningful significant differences were found among sexual behaviors. We found that youth who had engaged in sexting within a romantic relationship were significantly more likely to have ever had sexual contact than those who engaged in sexting outside of a 
romantic relationship. This finding adds to the argument that sexting may be part of modern day relationships.

Differences were found with regard to sexual risk behaviors. Single youth who were sexually active and engaged in sexting outside of a romantic relationship reported, on average, more lifetime sexual partners than those who engaged in sexting within the context of a romantic relationship. Future research should use more fine-grained measures to differentiate between types of partners (e.g., in a committed versus a casual relationship) to investigate if and how hook-up behaviors and sexual behaviors among adolescents are linked with sexting behaviors outside of romantic relationships. Future studies could also investigate which role sexting plays within the initiation of sexual contact among some adolescents. Single youth who were sexually active and engaged in sexting outside the context of a romantic relationship had more often used alcohol or drugs prior to their last sexual contact than those who engaged in sexting with their current romantic partner. We did not find a significant difference in the use of protection at the last sexual encounter. These findings further underscore the need for the integration of substance use prevention within sexual and relationship education.

\section{Limitations and Directions for Future Research}

Some limitations of our study should be kept in mind when interpreting results. Because of its cross-sectional nature, causality cannot be inferred and we are unable to determine the directionality of the variables. The relationship between different types of risk behaviors and sexting might be the byproduct of an underlying variable (such as personality traits or parenting styles) or they might be indicative of a similar life-style pattern (Temple et al. 2014). The use of a convenience sample also limits the generalizability of our findings. Future studies will benefit by using alternative participant recruitment and data collection strategies in order to minimize sampling bias. Our reliance on self-report data may have resulted in some respondents to over- or underreported their engagement in sexting or risk behaviors. It should be noted that some participants might have engaged in sexting with their romantic partner prior to having formally established their romantic relationship. Although they might retrospectively score this behavior as sexting within a romantic relationship, it could be in some cases scored as sexting within a romantic relationship even though they were engaging in sexting outside of a romantic relationship.

Future studies could inquire whether adolescents were pressured to engage in sexting, or specify the degree of familiarity with the receiver (e.g., romantic partner, friend, someone they never met in person). Moreover, the motives for youth to sext (e.g., whether the pictures were meant to be serious or as a joke) could be investigated. Depending on their motivation for sexting, it might be associated with different risks and consequently, at-risk adolescents might be more likely to engage in the behavior (e.g., flirting, versus bonding within a romantic relationship). Another approach might be to take into account the quality and strength of the relationship between the sender and the receiver of the sext. For example, one can argue that sexting within a committed relationship might be less risky than sending an image to a less committed partner. Furthermore, when analyzing adolescents' engagement in different contexts of sexting behavior, future research could focus on other social and personality related factors.

\section{Conclusions}

Despite the boom in research on sexting and its associations with risk behaviors, we still have a long way to go in fully understanding the public health significance of this emerging behavior. By taking into account the context in which sexting occurs, this study extends prior research on sexting and risk behaviors. Sexting with a romantic partner is not a significant marker of engagement in other types of risk behaviors. However, single youth who engage in sexting outside of a romantic relationship, engage more in almost all forms of substance use, relative to their peers who do not sext. Sexting might also function as a marker of being sexually active, compared to single non-sexting peers. The results of our study underscore the need to apply a more nuanced approach to measuring sexting behavior by taking into account the contexts in which sexting occurs.

Acknowledgements The authors would like to thank the undergraduate students Lien Maldoy, Esther Sikkens, and Moniek Wallink for their assistance with the data collection. The authors would also like to thank Dr. Jessica Taylor Piotrowski for her helpful feedback on this study during the ICA-CAM research escalator session at the 67th Annual International Communication Association Conference, 25-29 May 2017, San Diego, California, USA.

Authors' Contributions J.V.O. conceptualized and designed the study, coordinated and supervised the data collection, carried out the data analysis, interpreted the results, drafted the initial manuscript, and revised the manuscript. K.P. and M.W. participated in the design of the study. K.P., M.W., Y.L. and J.R.T. supervised the data analysis, assisted in the interpretation of the results, and revised the manuscript. All authors read and approved the final manuscript.

Funding The work of Dr. Joris Van Ouytsel is supported by the Research Foundation - Flanders. During a research stay at the University of Texas Medical Branch, Dr. Van Ouytsel was supported by a grant awarded by the Fulbright Commission in Belgium. The data collection for this study was supported by the Research Fund of the University of Antwerp (BOF DOC PRO 2013 - 41/FA040300/ FFB130145). The study design, data collection, analysis, interpretation of the data, writing of the report and the decision to submit the article for publication were the sole responsibility of the authors and were in no way influenced by the funding institutions. 
Data Sharing Declaration This manuscript's data will not be deposited.

\section{Compliance with Ethical Standards}

Conflict of Interest The authors declare that they have no conflict of interest.

Ethical Approval The study's protocol and the consent procedures were approved by the Ethical Committee of the University of Antwerp. All procedures performed in this study involving human participants were in accordance with the ethical standards of the institutional and/or national research committee and with the 1964 Helsinki declaration and its later amendments or comparable ethical standards.

Informed Consent Informed consent was obtained from all individual participants included in the study.

\section{References}

Agaston, P., Kowalski, R., \& Limber, S. (2012). Youth views on cyberbullying. In J. Patchin \& S. Hinduja (Eds.), Cyberbullying prevention and response: expert perspectives (pp. 57-71). New York, NY: Routledge.

Barrense-Dias, Y., Berchtold, A., Surís, J.-C., \& Akre, C. (2017). Sexting and the definition Issue. Journal of Adolescent Health, 61 (5), 544-554. https://doi.org/10.1016/j.jadohealth.2017.05.009.

Brinkley, D. Y., Ackerman, R. A., Ehrenreich, S. E., \& Underwood, M. K. (2017). Sending and receiving text messages with sexual content: relations with early sexual activity and borderline personality features in late adolescence. Computers in Human Behavior, 70, 119-130. https://doi.org/10.1016/j.chb.2016.12. 082.

Campbell, S. W., \& Park, Y. J. (2014). Predictors of mobile sexting among teens: toward a new explanatory framework. Mobile Media \& Communication, 2(1), 20-39. https://doi.org/10.1177/ 2050157913502645.

Centers for Disease Control and Prevention (2015). 2015 Youth Risk Behavior Survey. www.cdc.gov/yrbss.

Collins, W. A., Welsh, D. P., \& Furman, W. (2009). Adolescent romantic relationships. Annual Review of Psychology, 60(1), 631-652. https://doi.org/10.1146/annurev.psych.60.110707. 163459.

Cooper, K., Quayle, E., Jonsson, L., \& Svedin, C. G. (2016). Adolescents and self-taken sexual images: a review of the literature. Computers in Human Behavior, 55, 706-716. https://doi.org/10. 1016/j.chb.2015.10.003.

Dake, J. A., Price, J. H., Maziarz, L., \& Ward, B. (2012). Prevalence and correlates of sexting behavior in adolescents. American Journal of Sexuality Education, 7(1), 1-15. https://doi.org/10. 1080/15546128.2012.650959.

Dir, A. L., Cyders, M. A., \& Coskunpinar, A. (2013). From the bar to the bed via mobile phone: a first test of the role of problematic alcohol use, sexting, and impulsivity-related traits in sexual hookups. Computers in Human Behavior, 29(4), 1664-1670. https://doi.org/10.1016/j.chb.2013.01.039.

Drouin, M., Ross, J., \& Tobin, E. (2015). Sexting: a new, digital vehicle for intimate partner aggression? Computers in Human Behavior, 50(0), 197-204. https://doi.org/10.1016/j.chb.2015.04. 001.

Englander, E., \& McCoy, M. (2018). Sexting-prevalence, age, sex, and outcomes. JAMA Pediatrics, 172(4), 317-318. https://doi. org/10.1001/jamapediatrics.2017.5682.
Englander, E., \& McCoy, M. (2017). Pressured sexting and revenge porn in a sample of massachusetts adolescents. International Journal of Technoethics, 8(2), 16-25.

Englander, E. K. (2015). Coerced sexting and revenge porn among teens. Bullying, teen aggression \& social media 1(2) (March/ April), 19-21.

Gover, A. R. (2004). Risky lifestyles and dating violence: a theoretical test of violent victimization. Journal of Criminal Justice, 32(2), 171-180. https://doi.org/10.1016/j.jcrimjus.2003.12.007.

Houck, C. D., Barker, D., Rizzo, C., Hancock, E., Norton, A., \& Brown, L. K. (2014). Sexting and sexual behavior in at-risk adolescents. Pediatrics, 133(2), e276-e282. https://doi.org/10. 1542/peds.2013-1157.

Jessor, R., (2014). Chapter 23: Problem behavior theory. A halfcentury of research on adolescent behavior and development. In R. M. Lerner, A. C. Petersen, R. K. Silbereisen, J. Brooks-Gunn (Eds.) The developmental science of adolescence: history through autobiography. (pp. 239-256). New York, NY: Psychology Press.

Klettke, B., Hallford, D. J., \& Mellor, D. J. (2014). Sexting prevalence and correlates: a systematic literature review. Clinical Psychology Review, 34(1), 44-53. https://doi.org/10.1016/j.cpr.2013.10.007.

Kosenko, K., Luurs, G., \& Binder, A. R. (2017). Sexting and sexual behavior, 2011-2015: a critical review and meta-analysis of a growing literature. Journal of Computer-Mediated Communication, 22(3), 141-160. https://doi.org/10.1111/jcc4.12187.

Lee, C.-H., Moak, S., \& Walker, J. T. (2016). Effects of self-control, social control, and social learning on sexting behavior among south korean youths. Youth \& Society, 48(2), 242-264. https:// doi.org/10.1177/0044118x13490762.

Lippman, J. R., \& Campbell, S. W. (2014). Damned if you do, damned if you don't...if you're a girl: relational and normative contexts of adolescent sexting in the United States. Journal of Children and Media, 8(4), 371-386. https://doi.org/10.1080/17482798.2014. 923009.

Madigan, S., Ly, A., Rash, C. L., Van Ouytsel, J., \& Temple, J. R. (2018). Prevalence of multiple forms of sexting behavior among youth: a systematic review and meta-analysis. JAMA Pediatrics, 172(4), 327-335. https://doi.org/10.1001/jamapediatrics.2017. 5314.

McDaniel, B. T., \& Drouin, M. (2015). Sexting among married couples: Who is doing it, and Are they more satisfied? Cyberpsychology, Behavior, and Social Networking, 18(11), 628-634. https://doi.org/10.1089/cyber.2015.0334.

Melander, L., \& Hughes, V. (2018). College partner violence in the digitalage: explaining cyber aggression using routine activities theory. Partner Abuse, 9(2), 158-180. https://doi.org/10.1891/ 1946-6560.9.2.158.

Mitchell K. J., Finkelhor D., Jones L. M., \& Wolak J. (2012). Prevalence and Characteristics of YouthSexting: A National Study. Pediatrics, 129, 13-20.https://doi.org/10.1542/peds.2011-1730.

Olweus, D. (1999). Sweden. In P. K. Smith, Y. Morita, J. Junger-Tas, D. Olweus, R. Catalano \& P. Slee (Eds.), The nature of school bullying: a cross-national perspective (pp. 7-27). London, UK: Routledge.

Onrust, S. A., Otten, R., Lammers, J., \& Smit, F. (2016). School-based programmes to reduce and prevent substance use in different age groups: What works for whom? Systematic review and metaregression analysis. Clinical Psychology Review, 44, 45-59. https://doi.org/10.1016/j.cpr.2015.11.002.

Rice, E., Craddock, J., Hemler, M., Rusow, J., Plant, A., Montoya, J., \& Kordic, T. (2018). Associations between sexting behaviors and sexual behaviors among mobile phone-owning teens in Los Angeles. Child Development, 89(1), 110-117. https://doi.org/10. 1111/cdev.12837. 
Rice, E., Gibbs, J., Winetrobe, H., Rhoades, H., Plant, A., Montoya, J., $\&$ Kordic, T. (2014). Sexting and sexual behavior among middle school students. Pediatrics. https://doi.org/10.1542/peds.20132991.

Rice, E., Rhoades, H., Winetrobe, H., Sanchez, M., Montoya, J., Plant, A., \& Kordic, T. (2012). Sexually explicit cell phone messaging associated with sexual risk among adolescents. Pediatrics, 130 (4), 667-673. https://doi.org/10.1542/peds.2012-0021.

Ringrose, J., Gill, R., Livingstone, S., \& Harvey, L. (2012). A qualitative study of children, young people and'sexting': a report prepared for the NSPCC.

Ševčíková, A. (2016). Girls' and boys' experience with teen sexting in early and late adolescence. Journal of Adolescence, 51, 156-162. https://doi.org/10.1016/j.adolescence.2016.06.007.

Šmahel, D., \& Subrahmanyam, K. (2014). Adolescent sexuality on the internet: a developmental perspective. In F. M. Saleh, A. Grudzinskas \& A. M. Judge (Eds.), Adolescent sexual behavior in the digital age (pp. 62-85). Oxford: Oxford University Press.

Temple, J. R. (2015). A primer on teen sexting. JAACAP Connect, 2 (4), 6-8.

Temple, J. R., \& Choi, H. (2014). Longitudinal association between teen sexting and sexual behavior. Pediatrics, 134(5), e1287-e1292. https://doi.org/10.1542/peds.2014-1974.

Temple, J. R., Le, V. D., van den Berg, P., Ling, Y., Paul, J. A., \& Temple, B. W. (2014). Brief report: teen sexting and psychosocial health. Journal of Adolescence, 37(1), 33-36. https://doi.org/10. 1016/j.adolescence.2013.10.008.

Temple, J. R., \& Lu, Y. (2018). Sexting from a health perspective: sexting, health, and risky sexual behaviour. In M. Walrave, J. Van Ouytsel, K. Ponnet \& J. R. Temple (Eds.), Sexting: motives and risk in online sexual self-presentation (pp. 53-61). Cham: Springer International Publishing.

Temple, J. R., Paul, J. A., van den Berg, P., Le, V. D., McElhany, A., \& Temple, B. W. (2012). Teen sexting and its association with sexual behaviors. Archives of Pediatrics and Adolescent Medicine, 166. https://doi.org/10.1001/archpediatrics.2012.835.

Thomas, S. E. (2018). "What should i do?": young women's reported dilemmas with nude photographs. Sexuality Research and Social Policy, 15(2), 192-207. https://doi.org/10.1007/s13178-0170310-0.

Vanden Abeele, M., Campbell, S. W., Eggermont, S., \& Roe, K. (2014). Sexting, mobile porn use, and peer group dynamics: boys' and girls' self-perceived popularity, need for popularity, and perceived peer pressure. Media Psychology, 17(1), 6-33. https://doi.org/10.1080/15213269.2013.801725.

Valkenburg, P. M., \& Peter, J. (2013). The differential susceptibility to media effects model. Journal of Communication, 63(2), 221-243. https://doi.org/10.1111/jcom.12024.

Van Ouytsel, J., Ponnet, K., Walrave, M., \& d'Haenens, L. (2017). Adolescent sexting from a social learning perspective. Telematics and Informatics, 34(1), 287-298. https://doi.org/10.1016/j.tele. 2016.05.009.

Van Ouytsel, J., Van Gool, E., Ponnet, K., \& Walrave, M. (2014). Brief report: the association between adolescents' characteristics and engagement in sexting. Journal of Adolescence, 37(8), 1387-1391. https://doi.org/10.1016/j.adolescence.2014.10.004.

Van Ouytsel, J., Van Gool, E., Walrave, M., Ponnet, K., \& Peeters, E. (2017). Sexting: adolescents' perceptions of the applications used for, motives for, and consequences of sexting. Journal of Youth Studies, 20(4), 446-470. https://doi.org/10.1080/13676261.2016. 1241865.

Van Ouytsel, J., Walrave, M., \& Ponnet, K. (2018a). Adolescent sexting research: the challenges ahead. JAMA Pediatrics, 172(5), 405-406. https://doi.org/10.1001/jamapediatrics.2018.0013.

Van Ouytsel, J., Walrave, M., \& Ponnet, K. (2018b). A nuanced account: Why do individuals engage in sexting? In M. Walrave, J.
Van Ouytsel, K. Ponnet \& J. R. Temple (Eds.), Sexting: motives and risk in online sexual self-presentation (pp. 39-51). Cham: Springer International Publishing.

Van Ouytsel, J., Walrave, M., Ponnet, K., \& Heirman, W. (2015). The association between adolescent sexting, psychosocial difficulties, and risk behavior: integrative review. The Journal of School Nursing, 31(1), 54-69. https://doi.org/10.1177/ 1059840514541964.

Van Ouytsel, J., Walrave, M., \& Van Gool, E. (2014). Sexting: between thrill and fear - how schools can respond. The Clearing House: A Journal of Educational Strategies, Issues and Ideas, 87 (5), 204-212. https://doi.org/10.1080/00098655.2014.909380.

Walrave, M., \& Heirman, W. (2011). Cyberbullying: predicting victimisation and perpetration. Children \& Society, 25(1), 59-72. https://doi.org/10.1111/j.1099-0860.2009.00260.x.

West, J. H., Lister, C. E., Hall, P. C., Crookston, B. T., Snow, P. R., Zvietcovich, M. E., \& West, R. P. (2014). Sexting among peruvian adolescents. BMC Public Health, 14(1), 811 https://doi.org/ 10.1186/1471-2458-14-811.

Wolfe, D. A., Crooks, C., Jaffe, P., Chiodo, D., Hughes, R., Ellis, W., \& Donner, A. (2009). A school-based program to prevent adolescent dating violence: a cluster randomized trial. Archives of Pediatrics \& Adolescent Medicine, 163(8), 692-699. https://doi. org/10.1001/archpediatrics.2009.69.

Wolfe, S. E., Marcum, C. D., Higgins, G. E., \& Ricketts, M. L. (2016). Routine cell phone activity and exposure to sext messages: extending the generality of routine activity theory and exploring the etiology of a risky teenage behavior. Crimean \& Delinquency, 62(5), 614-644. https://doi.org/10.1177/0011128714541192.

Wood, M., Barter, C., Stanley, N., Aghtaie, N., \& Larkins, C. (2015). Images across Europe: the sending and receiving of sexual images and associations with interpersonal violence in young people's relationships. Children and Youth Services Review, 59, 149-160. https://doi.org/10.1016/j.childyouth.2015.11.005.

Ybarra, M. L., \& Mitchell, K. J. (2014). "Sexting" and its relation to sexual activity and sexual risk behavior in a national survey of adolescents. Journal of Adolescent Health, 55(6), 757-764. https://doi.org/10.1016/j.jadohealth.2014.07.012.

Ybarra, M. L., \& Mitchell, K. J. (2015). The authors reply. Journal of Adolescent Health, 57(1), 129 https://doi.org/10.1016/j.jadohea 1th.2015.04.014.

Joris Van Ouytsel is a postdoctoral researcher at the Department of Communication Studies at the University of Antwerp. He focuses his research on the influence of digital media on relationship experiences and sexuality among adolescents. More specifically, he investigates the role of sexting and cyber dating abuse, the use of digital media within romantic relationship to control or harass a romantic partner.

Michel Walrave is a Professor at the Department of Communication Studies, University of Antwerp. He is responsible for the research group MIOS. His research is centered around online self-disclosure and privacy. He investigates adolescents' and adults' online disclosure of personal information to other individuals, including intimate selfdisclosures such as sexting.

Yu Lu is a postdoctoral Research Fellow at UTMB Health in Galveston, Texas. She received her doctorate in Communication Arts 
and Sciences from the Pennsylvania State University. Her major research interests are health decision-making and health disparities, particularly in the context of risk behaviours such as violence and substance abuse.

Jeff R. Temple is a Professor at UTMB Health in Galveston, Texas. $\mathrm{He}$ received his doctorate in counselling psychology from the University of North Texas and a postdoctoral research fellowship at Brown University. His major research interests include the aetiology, course, consequences, prevention, and treatment of intimate partner and teen dating violence.

Koen Ponnet is an Assistant Professor at the Ghent University. He is (co-)author of multiple articles on the determinants of online and offline health and risk behaviors of adolescents and adults. In his research, he also pays attention to the situation of vulnerable groups, like those who are at risk of poverty. 